\title{
Understanding the use of decision support tools by conservation professionals and their education and training needs: An application of the Reasoned Action Approach
}

\author{
P. Ranjan, L.F. Duriancik, D.N. Moriasi, D. Carlson, K. Anderson, and L.S. Prokopy
}

\begin{abstract}
Decision support tools (DSTs) are a means to facilitate science-based conservation planning. Technical advancements in conservation science, the pragmatic needs of conservation planning, and government support for collaborative initiatives such as the Conservation Effects Assessment Project (CEAP), have contributed to evaluation and development of both existing and new DSTs. Much of current scholarship on DSTs, however, focuses on their uptake by farmers and their crop advisors. Limited, to almost no, attention has been paid to the education and training needs of conservation agency staff-the primary users of these tools. To address this knowledge gap, we conducted an online survey of staff in conservation agencies that are located in counties that either currently include or included a CEAP Watershed Assessment Study site. We found that agency staff did not use all DSTs, and not all DSTs we surveyed were equally popular with respect to their usage and awareness. The desired technical roles of DSTs included conservation targeting, watershed assessment and planning, and quantifying environmental and financial benefits of conservation practices. The desired stakeholder engagement roles of DSTs included facilitating engagement with watershed stakeholders, educating farmers about areas of concern in the watershed, and facilitating engagement with farmers one-on-one and in a group setting. By applying the Reasoned Action Approach framework, we found that DST users and nonusers are not only differently skilled, but also perceive barriers related to learning about and using DSTs differently. Taken together, our findings suggest the need for future research on establishing a deeper understanding of conservation agency staffs' skills, attitudes, perceived norms, behavioral limitations, and intentions toward using DSTs, in order to refine future training and education to better meet needs.
\end{abstract}

Key words: Conservation Effects Assessment Project (CEAP)—conservation planningstakeholder engagement-survey — technical roles-watershed assessment

The ability to balance farmers' production and conservation goals is a topic of great interest to professionals promoting conservation. The process of conservation planning involves conservation agency staff working with farmers to understand their farm management goals, natural resource management concerns and needs, and recommend conservation practices that can effectively address these concerns and goals. An essential component of the conservation planning process is conservation agency staff providing science-based technical assistance and recommendations to farmers; deci- sion support tools (DSTs) can help with this work. Defined broadly, DSTs are tools that facilitate effective, science-based decision-making by leading users through "clear decision stages and presenting the likelihood of various outcomes resulting from different options" (Rose et al. 2016). DSTs are usually user-friendly dynamic software tools that are geared toward field or point-scale applications or simply act as information sources (Rose et al. 2016).

In conservation planning, a significant technical challenge is the establishment of a connection between farm-scale conser- vation implementation and watershed-scale environmental outcomes (Tomer and Locke 2011). Most DSTs are used for field-scale analysis of conservation benefits, while estimating integrated water quality outcomes for a watershed is much more technically challenging. Therefore, scholars have identified the need for agricultural DSTs that can facilitate conservation planning within a watershed context, and help connect watershed-level benefits to field-scale conservation actions (Tomer et al. 2015). A related conservation planning goal is to increase effectiveness through precision placement of conservation practices within Critical Source Areas (CSAs), i.e., areas within the watershed that may have greater inherent risk and could cause a disproportionate amount of environmental degradation. Identifying practices that can be most effective for specific constituents, sources, and transport pathways is critical to effective conservation (Osmond et al. 2012). New DSTs are emerging, which can help conservation agency staff evaluate and prioritize placement of conservation practices that will be effective for specific water quality concerns to CSAs within a watershed context (McLellan et al. 2018). Advances in modeling and automated data capture in the field have further fueled the design and development of DSTs (Cerf et al. 2012).

While natural resource management challenges related to conservation planning provide a practical rationale for the design and development of DSTs, new DSTs have also emerged or been refined as a result of government support for collaborative initiatives such as the Conservation Effects

Pranay Ranjan (corresponding author), postdoctoral research associate, Department of Forestry and Natural Resources, Purdue University, West Lafayette, Indiana. Lisa F. Duriancik, Conservation Effects Assessment Project (CEAP) Watershed assessment studies component leader, USDA Natural Resources Conservation Service (NRCS) Resource Inventory and Assessment Division, Outcomes Team, Beltsville, Maryland. Daniel N. Moriasi, research hydrologist, USDA Agricultural Research Service (ARS) Grazinglands Research Laboratory, El Reno, Oklahoma. Dee Carlson, conservation initiative coordinator (Mississippi River Basin Initiative, National Water Quality Initiative), USDA NRCS, Washington, DC. Karma Anderson, national water quality and quantity team leader, USDA NRCS, Portland, Oregon. Linda S. Prokopy, professor, Department of Forestry and Natural Resources, Purdue University, West Lafayette, Indiana. 


\section{Figure 1}

Conservation Effects Assessment Project (CEAP) Watershed Assessment Studies sites. ARS = Agricultural Research Service, NIFA = National Institute of Food and Agriculture, NRCS = Natural Resources Conservation Service, USGS = US Geological Survey, and NOAA = National Oceanic and Atmospheric Administration. Source: USDA NRCS, Resource Inventory and Assessment Division.

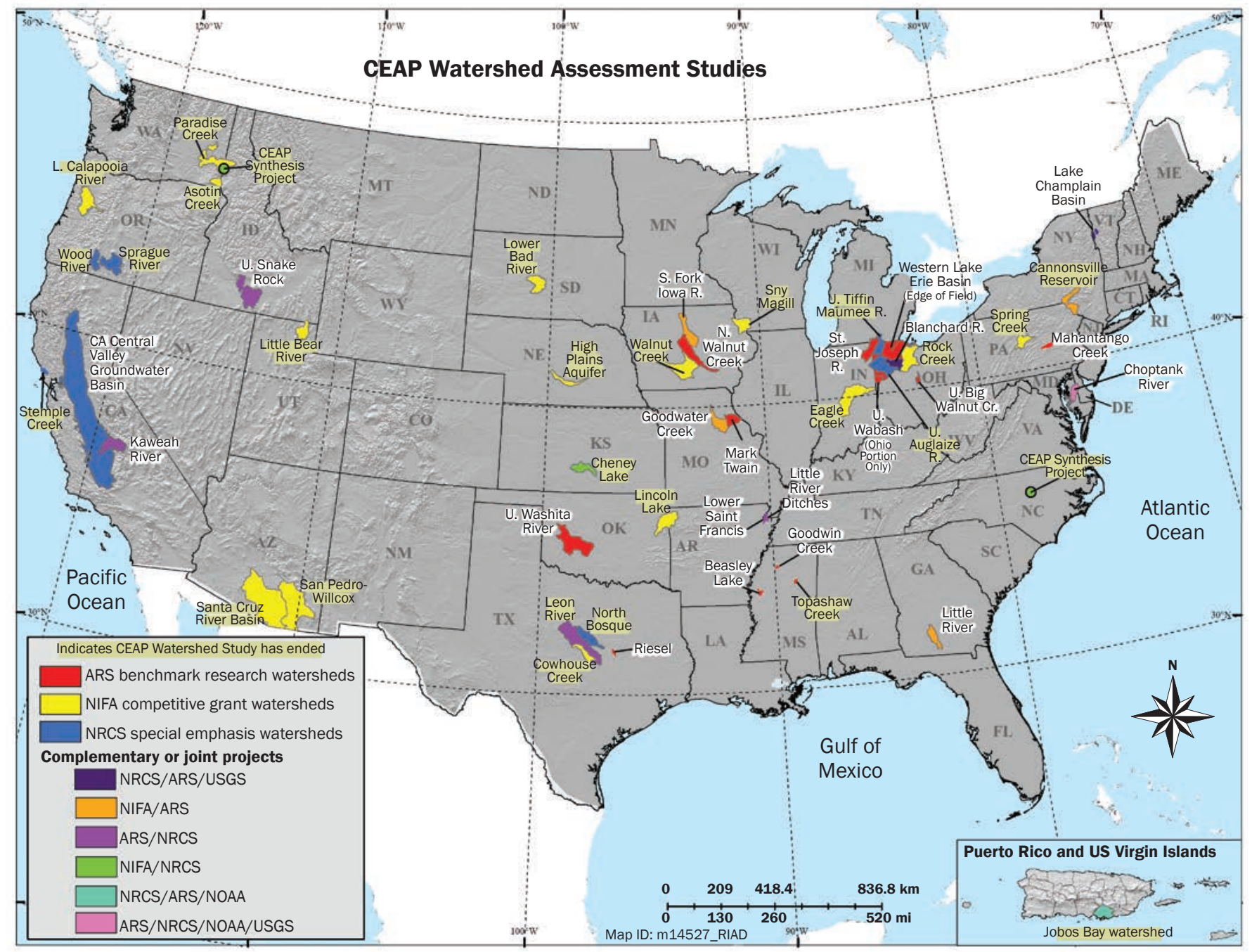

Assessment Project (CEAP). CEAP, a joint initiative of the USDA Natural Resources Conservation Service (NRCS), USDA Agricultural Research Service (ARS), USDA National Institute of Food and Agriculture (NIFA), and USDA Farm Service Agency (FSA), in collaboration with universities, nongovernmental organizations, farmers, and other partners, provided assessments and quantification of the effects of conservation practices at the watershed scale (Duriancik et al. 2008). The CEAP Watershed Assessment Studies (CEAP-WAS), a national network of small watershed assessments (figure 1), resulted in numerous advances in knowledge relative to conservation science, and stimulated evaluation and development of both existing and new DSTs with the goal of helping conservationists assess a range of water quality resource concerns within watersheds (Maresch et al. 2008). Examples of DSTs either evaluated, validated, or developed using data or insights from CEAP include Revised Universal Soil Loss Equation (RUSLE2; Dabney et al. 2011), Phosphorus Index (PI; Kleinman et al. 2017), and Agricultural Conservation Planning Framework (ACPF; Tomer et al. 2015). Advancements in the evaluation and development of DSTs, however, did not correspond with advancements in understanding the educational and training needs of conservation agency staff-the primary users of these DSTs. Although agency staff may typically use farm-scale
DSTs for on-farm planning, familiarity with and usage of watershed- and landscape-scale DSTs could help them with area-wide planning needs.

Overall, the current scholarship on DSTs pays limited, to almost no, attention to the education and training needs of conservation agency staff. Agency staff often have to set up and run DSTs, and more importantly use DST results to facilitate science-based decision-making by farmers, making it imperative that we draw scholarly attention to this topic. With the goal of identifying the education and training needs of DST users and nonusers, we present findings from an online survey of conservation agency staff working in counties that include or included 
a CEAP-WAS. The overarching questions of this study are (1) what is the level of usage and awareness of DSTs among conservation agency staff, and (2) whether and how do DST users and nonusers differ in terms of their motivations for and barriers to engaging in DST related behaviors? By addressing these questions, conservation organizations should be able to better meet their staff's training and education needs to increase use of water quality planning DSTs, and help farmers balance production and conservation goals.

\section{Materials and Methods}

Description of the Survey. The data for this study come from an online survey conducted by Purdue University of staff working in conservation organizations that are located in a county that either currently includes or included a CEAP-WAS site. The population of interest consisted of agency staff in these counties who are working in the field of conservation, which included but was not limited to conservation planning. This was assessed based on their job designation. For example, staff with designations such as resource conservationist, soil conservationist, district conservationist, etc., were included in our sample. Also included in the sampling frame were conservation technical support positions such as soil scientist, agricultural and civil engineer, etc. Staff with administrative designations such as administrative assistant and district secretary were excluded.

We focused on staff in CEAP-WAS sites because they are more likely to be aware of and use DSTs. This assertion seems plausible because CEAP stimulated evaluation and development of both existing and new DSTs. Moreover, given our focus on understanding the education and training needs of agency staff in CEAP watersheds, our sampling criterion fits the research objectives of this study. Based on our sampling criterion, we administered our survey in Soil and Water Conservation Districts (SWCD) and USDA NRCS offices in 231 counties spread across 24 states, and 8 municipalities in Puerto Rico. For consistency and ease of presenting data, we are referring to the 8 municipalities as counties. A sampling frame was generated by searching online for conservation agency staff working in these counties. USDA NRCS staff were predominantly identified using the USDA Service Center employee directory. SWCD staff were predominantly identified through their agency's website. The initial sampling frame had 1,178 agency staff. After removing duplicate names and email addresses from the list, the final sample was reduced to 1,022 agency staff.

The survey instrument was conceptually grounded in, and subsequently designed, based on the Reasoned Action Approach (RAA) framework (Fishbein and Ajzen 2011), formerly called the Theory of Planned Behavior (TPB). The survey was designed to operationalize several RAA constructs, including perceived social norms, attitude toward performing the behavior, perceived behavioral control, lack of actual control over performance of the behavior, and behavioral intention. For the purpose of this study, behaviors relevant to the usage of DSTs are agency staff attending training session(s) to learn about DSTs, running the DSTs themselves, using DST results to engage with producers, and participating in training sessions on watershed assessment and planning.

The survey was distributed in five waves, i.e., an initial survey invite was sent along with a confidential survey link, followed by four reminders (Dillman et al. 2014). The fourth and final reminder was sent only to USDA employees. The survey was administered using Qualtrics (Qualtrics, Provo, Utah), an online survey dissemination portal Of the 1,022 surveys that were emailed, 20 emails bounced. Of the 1,002 valid survey emails, 291 surveys were taken, resulting in a 29.04\% response rate (Vaske 2008). Data analysis was conducted in SPSS (version 24), and included the following: descriptive statistics, a comparative and descriptive investigation of DST users' and nonusers' perception of the roles DSTs should fulfill in conservation planning, and Mann-Whitney $U$ tests to investigate mean differences between DST users and nonusers with respect to several RAA constructs. A nonparametric test was used because Likert scale data are not normally distributed.

Survey respondents were presented with the following background information about DSTs before taking the survey:"Conservation agency staff often have to deal with the challenge of establishing a connection between field-scale conservation efforts and the resulting watershed scale environmental outcomes. To that end, the United States Department of Agriculture Natural Resources Conservation Service (NRCS) and the Agricultural Research Service (USDA ARS) have devel- oped Decision-Support Tools (DSTs) to help conservation staff evaluate a range of natural resource concerns across watersheds. Examples include, RUSLE2 (Revised Universal Soil Loss Equation), WEPS (Wind Erosion Prediction System), and ACPF (Agricultural Conservation Planning Framework)." Survey respondents were then asked, "Do you use any Decision Support Tools?" with "Yes" and "No" response options. If a respondent chose the option "Yes," they were classified as DST users. If a respondent chose the option "No," they were classified as DST nonuser. Specifically, for the purposes of the analysis reported in this study, we define DST users as those who indicated they currently use DSTs, and DST nonusers as those who are either aware of them, but do not use them currently, or they have not heard of any DSTs.

DSTs Surveyed in this Study. In the survey, we asked DST users to indicate their usage of 12 existing or new DSTs that have been evaluated and/or improved using data sets from the CEAP-WAS sites or other CEAP efforts (Duriancik et al. 2008). The DSTs selected for the survey are not all inclusive of DSTs that have been informed by CEAP. These were selected as a set of DSTs that are thought either to be more commonly used by conservation planners, or to include examples of newer DSTs that might have been used in a CEAP-WAS, even though these newer DSTs may not have been used outside of specific projects. A brief description with corresponding references is provided in table 1.

\section{Results and Discussion}

Demographics and Background Information. The results of the survey demographics are presented in table 2. Most respondents were highly educated, with $67.2 \%(n=137)$ holding a bachelor's degree and $18.1 \%(n=37)$ holding a master's degree. Out of those who had a bachelor's degree, $71.5 \%(n=98)$ had a bachelor's degree in natural sciences or other fields closely related to watershed management. Out of those who had a master's degree, $73 \%(n=27)$ had a master's degree in natural sciences or other fields closely related to watershed management. Most survey respondents were male $(66 \% ; n$ $=128)$, followed by $31.4 \%(n=61)$ female respondents, and the remaining respondents either identified themselves as nonbinary, neutral, or chose not to answer (2.6\%). The 
Table 1

Decision support tools (DST) enhanced by or that have benefitted from Conservation Effects Assessment Project (CEAP) assessments or data (not all-inclusive).

Decisionsupporttols(DST)enhanced by r thathave benefitted from Conservation Effects Assessment Project(CAP) ass

Decision support tool

Brief description

1. Revised Universal Soil Loss Equation, Version 2 (RUSLE2; Foster et al. 2001)

RUSLE2 (Foster et al. 2001), an upgrade of RUSLE (Renard et al. 1991), is a public domain program developed to evaluate potential erosion rates at specific sites as well as guide conservation and erosion control planning. USDA Agricultural Research Service (ARS) is the lead agency for developing the RUSLE2 model and has been applied in many CEAP study sites (Dabney et al. 2011).

2. Pasture Condition Score (PCS; Cosgrove et al. 2001; Sanderson et al. 2009)

The PCS tool was developed by the USDA Natural Resources Conservation
Service (NRCS) (Cosgrove et al. 2001) to monitor and assess pastureland enrolled in conservation programs (Sanderson et al. 2009). It involves the visual assessment of 10 indicators including percentage desirable plants, plant cover, plant residue, plant diversity, plant vigor, livestock concentration areas, erosion, wind, percentage legume, and soil compaction.

3. Phosphorous Index (PI; The $\mathrm{Pl}$ is a tool developed to help conservation planners, landowners/ Lemunyon and Gilbert 1993; land-users, and others to evaluate the current risk from phosphorus (P) Sharpley et al. 2003) reaching surface water from a specific site, and to determine factors, which dominate the risk due to $\mathrm{P}$ transport to surface waters. It has been applied or evaluated in several CEAP sites (Kleinman et al. 2017).

4. Wind Erosion Prediction System (WEPS; Hagen et al. 1995; Webb et al. 2016)

The WEPS model is a process-based, daily time-step model that simulates weather, field conditions, and wind erosion on croplands (Hagen et al. 1995). This model contains six modules that include daily weather simulator along with an hourly wind speed simulator, crop growth, residue decomposition, hydrology, soil status, and management operations (Webb et al. 2016).

5. Rangeland Health Assessment (RHA; Pellant et al. 2005)

RHA is one of the USDA NRCS tools developed and updated by NRCS in collaboration with ARS, Bureau of Land Management, and US Geological Survey (USGS) (Pellant et al. 2005) whose qualitative assessments of rangeland health provide land managers and technical assistance specialists with a good communication tool for use with the public. In this tool, ecological processes are described relative to reference states for the ecological sites being evaluated, requiring a reference sheet describing the range of spatial and temporal variability expected for soils and plant communities in the reference state within each ecological site.

6. Nutrient Tracking Tool (NTT; Saleh et al. 2011)

\section{The Nutrient Tracking Tool (NTT) is a user-friendly web-based computer} program developed to document nutrient trading credits. NTT provides users, primarily watershed coordinators and others responsible to track credits, with a computer interface to compare the effects of two scenarios, practice combinations, or other alternative conditions on indicators of interest using multiple years of historical or simulated weather data (Saleh et al. 2011). The Agricultural Policy Environmental eXtender (APEX) model (Williams and Izaurralde 2005) is the computation engine for the NTT interface. Recently, the USDA ARS along with others developed a framework to parameterize and validate APEX to support nation-wide deployment of NTT (Moriasi et al. 2016) and tested using Ohio CEAP data.

7. Soil Vulnerability Index (SVI; USDA NRCS 2012)

SVI was developed by the USDA NRCS as part of the CEAP Cropland to rank soils
nationwide with respect to their inherent vulnerability to contaminant transport by surface runoff or by leaching when cropped. This index has been tested in a number of recent CEAP studies (Chan et al. 2017; Lee et al. 2018; Thompson et al. 2020) utilizing CEAP Watershed data sets.

\section{Water Erosion Prediction} Project (WEPP) Model (Flanagan and Livingston 1995; Flanagan et al. 2012)
WEPP is a distributed parameter model run in a hillslope profile or a small watershed configuration (Flanagan and Livingston 1995; Flanagan et al. 2012). This tool was developed for agricultural lands as a replacement for the USLE/ RUSLE tools. This tool has the ability to simulate spatially varying land use and soil properties over different hillslope and watershed components, and compute sediment deposition and delivery as well as soil detachment. Data from St. Joseph River watershed has been used for WEPP application (Cechova et al. 2010).
Availability, documentation, and level of difficulty for conservation planning use by conservation agency staff

NRCS-supported versions available on desktop; field-level assessments; low-level complexity.

NRCS-supported versions available on desktop; field-level assessments; low-level complexity.

NRCS-supported versions available on desktop; field-level assessments; low-level complexity.

NRCS-supported versions available on desktop; field-level assessments; low-level complexity.

Available on desktop or hard copy; training available to NRCS; low-level complexity. Site-specific level (range).

Not readily available to NRCS; multiple versions; needs database and regional parameterization; moderate-level complexity. Field scale. Available; NRCS review on-going during survey period; low-level complexity. Based on field properties. Field level assessment can be aggregated more broadly.

Available on desktop, no NRCS certified executable; requires significant database development and calibration for use; online modifications; high-level complexity. Field and catchment-level assessment.

Table continued 


\begin{tabular}{|c|c|c|}
\hline Decision support tool & Brief description & $\begin{array}{l}\text { Availability, documentation, } \\
\text { and level of difficulty for } \\
\text { conservation planning use by } \\
\text { conservation agency staff }\end{array}$ \\
\hline $\begin{array}{l}\text { 9. Agricultural Conservation } \\
\text { Planning Framework (ACPF; } \\
\text { Tomer et al. 2015) }\end{array}$ & $\begin{array}{l}\text { ACPF is a watershed-scale assessment tool conceptually based on CEAP } \\
\text { Watershed targeting findings that utilizes spatial digital elevation, soils, and } \\
\text { land use data, readily available in central and northern United States. Spatial } \\
\text { data is combined with knowledge of conservation effectiveness to identify alter- } \\
\text { natives to reduce nutrient discharge from small watersheds (Tomer et al. 2015). } \\
\text { Tested in several CEAP Watersheds in lowa, Indiana, Ohio, and Pennsylvania. }\end{array}$ & $\begin{array}{l}\text { Available on desktop-GIS; requires } \\
\text { significant database development } \\
\text { for use; moderate-level complexity. } \\
\text { Watershed-scale assessment and } \\
\text { fields within. }\end{array}$ \\
\hline $\begin{array}{l}\text { 10. Stewardship Tool for } \\
\text { Environmental Performance } \\
\text { (STEP; Norfleet et al. 2015) }\end{array}$ & $\begin{array}{l}\text { STEP is a decision support tool developed by USDA NRCS (Norfleet et al. 2015). } \\
\text { STEP is generally based on the APEX (Williams and Izaurralde 2005) runs, } \\
\text { drawing on data created through CEAP model, runs and uses NRCS } \\
\text { conservation, soils, and agronomic expertise to support field-level planning. } \\
\text { This tool helps conservation planners evaluate relative water quality benefits } \\
\text { of land management and conservation practices for a given soil and climate. }\end{array}$ & $\begin{array}{l}\text { Not available as a standalone tool- } \\
\text { embedded in NRCS Resource } \\
\text { Stewardship Evaluation Tool (not } \\
\text { currently active online); low-level } \\
\text { complexity. Field-level assessment. }\end{array}$ \\
\hline $\begin{array}{l}\text { 11. Hydrologic } \\
\text { Characterization Tool } \\
\text { (HCT; Brooks et al. 2015). }\end{array}$ & $\begin{array}{l}\text { The web-based HCT (http://wepp.ag.uidaho.edu/cgi-bin/HCT.pl) is a simplified } \\
\text { version of the WEPP model developed to assist managers locate and select } \\
\text { effective land management practices (Brooks et al. 2015). This tool was } \\
\text { validated in a CEAP Watershed synthesis project and was applied to many } \\
\text { CEAP-WAS data sets. }\end{array}$ & $\begin{array}{l}\text { Available online but only for NIFA- } \\
\text { CEAP Watersheds; moderate-level } \\
\text { complexity. Watershed scale. }\end{array}$ \\
\hline $\begin{array}{l}\text { 12. Spreadsheet Tool for } \\
\text { Estimation of Pollutant Loads } \\
\text { (STEPL; Liu et al. 2017) }\end{array}$ & $\begin{array}{l}\text { The STEPL is a tool developed by Tetra Tech, Inc. for US Environmental } \\
\text { Protection Agency (USEPA), and uses simple algorithms or look up tables (there } \\
\text { are different versions in use) to calculate nutrient and sediment loads from } \\
\text { different land uses and the load reductions that would result from the } \\
\text { implementation of various best management practices (BMPs). Details are } \\
\text { provided on the USEPA website http://it.tetratech-ffx.com/steplweb/default.htm. } \\
\text { Purdue University provides an updated version online. }\end{array}$ & $\begin{array}{l}\text { Available online; moderate-level } \\
\text { complexity. Field-level aggregated to } \\
\text { watershed scale. }\end{array}$ \\
\hline
\end{tabular}

average age of survey respondents was 46.7 years (ranging from 20 to 76). On average, survey respondents had been working for the organization/agency of their current affiliation for 15.8 years $(N=204$; ranging from 5 months to 41 years). On average, survey respondents had been working in the field of conservation/conservation planning for 17 years $(N=204$; ranging from 6 months to 52 years). Overall, we can infer that survey respondents were highly educated with extensive experiential knowledge of conservation planning. More than half of survey respondents $(54.3 \% ; n=114)$ had also participated in training sessions on watershed assessment and planning.

Slightly more than half of survey respondents indicated they currently used DSTs $(53 \% ; n=150)$. These 150 respondents were classified as DST users. Out of the remaining $47 \%(n=134)$ of respondents who do not use DSTs, $22.4 \%(n=30)$ had at least heard of them; the remaining $77.6 \%(n=$ 104) of respondents had not heard of DSTs. These 134 respondents were classified as DST nonusers. Comparative demographics and background data between DST users and nonusers are presented in table 2. Among DST users, $83.3 \%(n=125)$ were from USDA NRCS, and the remaining $16.7 \%(n=25)$ were from an SWCD. Among DST nonusers, $72.9 \%(n=97)$ were from USDA NRCS, and the remaining $27.1 \%(n=36)$ were from an SWCD. Approximately 64\% $(n=195)$ of the survey respondents, both DST users and nonusers, had direct conservation planning responsibilities, assessed based on their designation. Specifically, 69.3\% $(n=104)$ among DST users and $56.8 \%(n=75)$ among DST nonusers had direct conservation planning responsibilities. A majority of the survey respondents, both DST users and nonusers, held one of the following three designations: district conservationist, soil conservationist, or soil conservationist technician.

DST Related Behaviors of Current DST Users. Almost all current users used DSTs as part of their professional responsibilities (table 3).A majority $(69.3 \% ; n=97)$ of DST users had participated in formal training(s) on DSTs. A majority $(70.3 \% ; n=97)$ of DST users had also used output maps/data sets from DSTs for education and outreach with farmers. Slightly less than half $(48.6 \% ; n$
$=67$ ) of DST users had used DST results for education and outreach with other types of stakeholders in the watershed. Overall, these findings are indicative of a high level of interest among DST users to use output maps/ data sets from DSTs to engage with watershed stakeholders, including farmers.

Usage and Awareness of DSTs among DST Users. DSTs surveyed in this study were classified under the following four categories: commonly used, not commonly used but somewhat known, not used but somewhat known, and neither used nor somewhat known. The following four fieldscale DSTs were commonly used: RUSLE2, Pasture Condition Score (PCS), PI, and Wind Erosion Prediction System (WEPS) (table 4). Ninety percent of DST users either do or have used RUSLE2 and nearly $70 \%$ use or have used PCS. Similarly, little over 50\% DST users either do or have used PI and WEPS. The following four DSTs were not commonly used but somewhat known: Rangeland Health Assessment (RHA), Nutrient Tracking Tool (NTT), Soil Vulnerability Index (SVI), and Watershed Erosion Prediction Project (WEPP). Three 


\section{Table 2}

Survey respondent demographics and background.

\begin{tabular}{|c|c|c|c|}
\hline Demographics & All respondents & DST users & DST nonusers \\
\hline \multicolumn{4}{|l|}{ Education $(N=204)$} \\
\hline Four-year college degree (\%) & $67.2(n=137)$ & $72(n=77)$ & $61.1(n=58)$ \\
\hline Graduate degree (\%) & $18.1(n=37)$ & $18.7(n=20)$ & $17.9(n=17)$ \\
\hline $\begin{array}{l}\text { Bachelor's degree in natural sciences or } \\
\text { other fields closely related to watershed } \\
\text { management (\%)* }\end{array}$ & $71.5(n=98)$ & $75.3(n=58)$ & $67.2(n=39)$ \\
\hline $\begin{array}{l}\text { Master's degree in natural sciences or } \\
\text { other fields closely related to watershed } \\
\text { management (\%) } \dagger\end{array}$ & $73(n=27)$ & $70(n=14)$ & $76.5(n=13)$ \\
\hline \multicolumn{4}{|l|}{ Gender $(N=194)$} \\
\hline Male $(\%)$ & $66(n=128)$ & $67.3(n=70)$ & $64(n=57)$ \\
\hline Female (\%) & $31.4(n=61)$ & $29.8(n=31)$ & $33.7(n=30)$ \\
\hline $\begin{array}{l}\text { Nonbinary, neutral, or chose not to } \\
\text { answer (\%) }\end{array}$ & $2.6(n=5)$ & $3.0(n=3)$ & $2.2(n=2)$ \\
\hline \multicolumn{4}{|l|}{ Age $(N=196)$} \\
\hline Mean age (y) & 46.71 & 46.48 & 46.97 \\
\hline Age range $(y)$ & 20 to 76 & 20 to 76 & 23 to 67 \\
\hline $\begin{array}{l}\text { Conservation/conservation planning } \\
\text { experience (y) }(N=204)\end{array}$ & 17.03 & 18.03 & 15.79 \\
\hline
\end{tabular}

Notes: DST = decision support tool.

*Only reported by a subset of respondents who had a four-year college degree.

†Only reported by a subset of respondents who had a graduate degree.

\section{Table 3}

Decision support tool (DST)-related behaviors of current users.

\begin{tabular}{|c|c|c|}
\hline Question & Yes (\%) & $n$ \\
\hline Do you use DSTs as part of your professional responsibilities? $(N=140)$ & 92.9 & 130 \\
\hline Have you participated in formal training(s) on DSTs? $(N=140)$ & 69.3 & 97 \\
\hline $\begin{array}{l}\text { Have you used output maps/data sets from DSTs for education and } \\
\text { outreach with farmers? }(N=138)\end{array}$ & 70.3 & 97 \\
\hline $\begin{array}{l}\text { Have you used output maps/data sets from DSTs for education and } \\
\text { outreach with other types of stakeholders in the watershed? }(N=138)\end{array}$ & 48.6 & 67 \\
\hline
\end{tabular}

of these four DSTs are either not readily available or not certified for use on USDA computers presently (table 1). These four DSTs had a combined score of at least $50 \%$ or more current and past users, and those who have at least heard about the DST. The following two newer DSTs were not used but somewhat known: ACPF and Stewardship Tool for Environmental Performance (STEP). These two DSTs scored very low on current and past usage $(\leq 10 \%)$. The last two DSTs were neither used nor somewhat known: Hydrologic Characterization Tool (HCT) and Spreadsheet Tool for Estimation of Pollutant Loads (STEPL). A vast majority of survey respondents $(>70 \%)$ had never heard of these DSTs. Overall, we found a great deal of diversity in both current and past usage of DSTs as well as DSTs that are known but not used. We also identified DSTs that conservation agency staff have not heard of; most of those are newer DSTs or watershed-scale DSTs, or are not readily available for use on USDA computers (table 1).

Reasoned Action Approach (RAA) Framework and DSTs: Desired Roles of DSTs and DST Related Skills and Abilities. In this study, we were interested in learning about conservation agency staffs' perceptions of the DSTs' roles in conservation planning. Survey respondents were presented a set of eight technical and five stakeholder engagement roles and were asked to indicate their level of disagreement or agreement with the presented set of roles DSTs should fulfill. Overall, both DST users and nonusers agreed (average rating between $3=$ agree and $4=$ strongly agree) that DSTs should fulfill the roles presented in the survey (table 5).

We were also interested in learning whether DST users and nonusers perceived themselves to be skilled at, and having the abilities to, engage in the conservation planning roles they desire DSTs to fulfill. Theoretically, the RAA framework differentiates between a respondent having actual control over performance of the behavior versus their perceived behavioral control (PBC), i.e., a respondent's sense of high or low self-efficacy to perform a behavior (Fishbein and Ajzen 2011). In this study, we operationalized actual control by asking respondents about their technical and stakeholder engagement skills and abilities (statements 1 to 8; table 6). We operationalized PBC by asking respondents about their perceived technical skills to run DSTs and their perceived ability to effectively communicate DST results to farmers (statements 1 and 2 ; table 6 ).

We found that DST users were relatively more skilled than DST nonusers. For example, a comparison between respondents' ability to use output/results from geographic information system (GIS) based DSTs to engage with farmers, measured on a scale of 1 (strongly disagree) to 5 (strongly agree), had a mean score of 3.75 ( $\mathrm{SD}=0.69, n=$ 108) for DST users and a mean score of $3.27(\mathrm{SD}=0.73, n=97)$ for DST nonusers. We conducted a Mann-Whitney U test to determine whether there was a statistical difference between DST users and nonusers with respect to their technical and stakeholder engagement skills. Results indicated that DST users are significantly more capable of using outputs/results from GIS based DSTs to engage with farmers than DST nonusers $(Z=-4.75, p<0.001)$. Similarly, a Mann-Whitney U test indicated that DST users are significantly more proficient in using common analytical tools (e.g., GIS, hydrologic and sediment transport models) than DST nonusers $(Z=-2.35, p=0.019)$.

Having the aforementioned skills and abilities also made DST users perceive themselves to be significantly more self-efficacious, i.e., capable, to engage in behaviors related to learning about and using DSTs than DST nonusers. For example, DST users scored significantly higher on the factor that they have the technical skills to run the DSTs compared to DST nonusers $(Z=-5.85, p$ 
Table 4

Usage and awareness of decision support tools (DSTs).

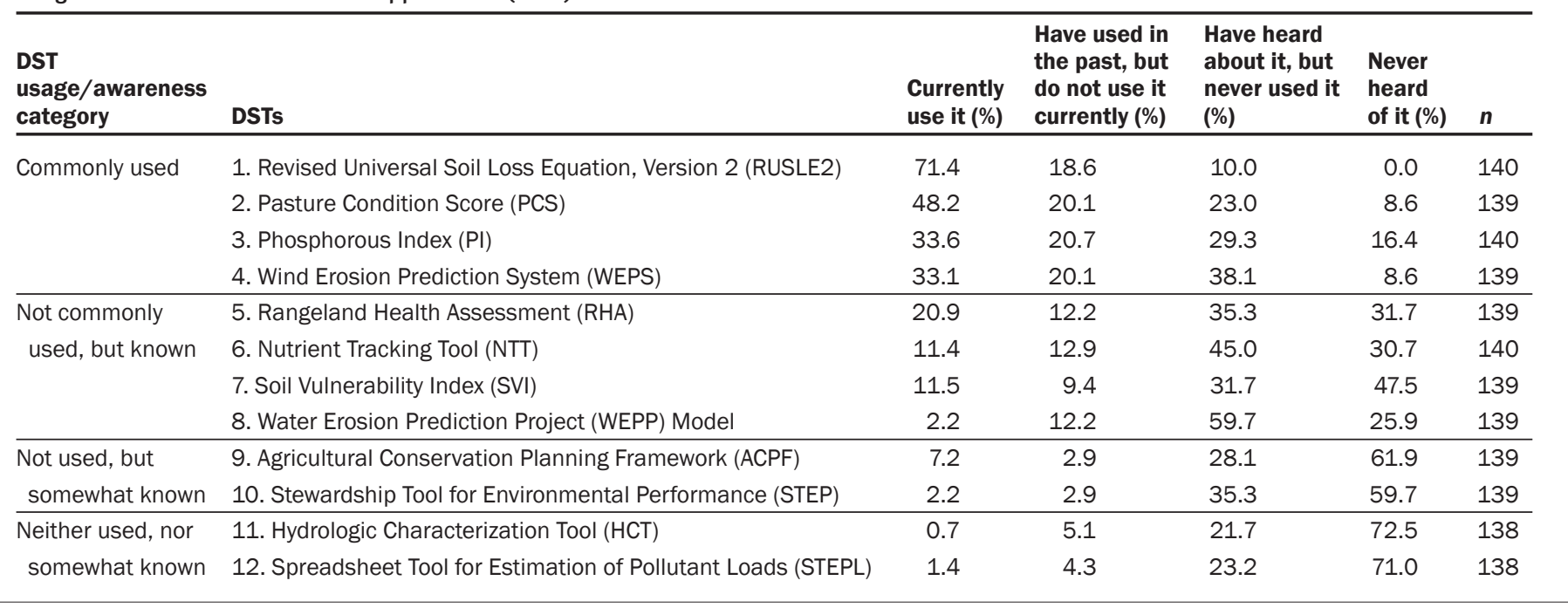

\section{Table 5}

Desired technical and stakeholder engagement roles of decision support tools (DSTs).

\begin{tabular}{|c|c|c|c|c|c|}
\hline DST roles & Survey items & DST users $¥$ (SD) & $n$ & DST nonusers§ (SD) & $n$ \\
\hline \multirow[t]{8}{*}{ Technical roles* } & 1. Identify areas of concern within the watershed & $3.13(0.67)$ & 104 & $3.27(0.59)$ & 81 \\
\hline & 2. Target conservation practices at a field scale & $3.25(0.71)$ & 110 & $3.20(0.64)$ & 75 \\
\hline & 3. Target conservation practices at a HUC12 watershed scale & $2.91(0.77)$ & 90 & $3.10(0.60)$ & 69 \\
\hline & 4. Provide project justification when applying for grants & $3.16(0.72)$ & 94 & $3.26(0.55)$ & 73 \\
\hline & 5. Help create watershed management plan & $3.20(0.59)$ & 95 & $3.27(0.59)$ & 79 \\
\hline & 6. Help in watershed planning & $3.22(0.64)$ & 95 & $3.25(0.56)$ & 80 \\
\hline & $\begin{array}{l}\text { 7. Quantify environmental benefits associated with adoption } \\
\text { of conservation practices }\end{array}$ & $3.31(0.62)$ & 107 & $3.20(0.65)$ & 79 \\
\hline & $\begin{array}{l}\text { 8. Quantify financial benefits associated with adoption of } \\
\text { conservation practices }\end{array}$ & $3.04(0.83)$ & 102 & $3.08(0.66)$ & 77 \\
\hline \multirow{5}{*}{$\begin{array}{l}\text { Stakeholder } \\
\text { engagement } \\
\text { roles† }\end{array}$} & 1. Facilitate engagement with stakeholder groups in the watershed & $2.96(0.69)$ & 90 & $3.04(0.46)$ & 70 \\
\hline & $\begin{array}{l}\text { 2. Facilitate discussion of conservation opportunities/options } \\
\text { one-on-one with farmers }\end{array}$ & $3.21(0.67)$ & 102 & $3.18(0.54)$ & 72 \\
\hline & $\begin{array}{l}\text { 3. Facilitate discussion of conservation opportunities/options } \\
\text { with farmers in a group setting }\end{array}$ & $3.12(0.73)$ & 100 & $3.07(0.51)$ & 74 \\
\hline & $\begin{array}{l}\text { 4. Facilitate educating farmers about areas of concern in } \\
\text { the watershed }\end{array}$ & $3.16(0.70)$ & 103 & $3.21(0.55)$ & 73 \\
\hline & 5. Help balance a farmer's production and conservation goals & $3.16(0.71)$ & 103 & $3.16(0.61)$ & 76 \\
\hline \multicolumn{6}{|c|}{$\begin{array}{l}\text { *Original survey question(s): Below is a list of technical roles DSTs can fulfill in conservation planning. When providing a response, please think } \\
\text { of DSTs you are familiar with. Please indicate your level of disagreement or agreement with the technical roles DSTs should fulfill. Measured on a } \\
\text { 4-point scale, where } 1=\text { strongly disagree, } 2=\text { disagree, } 3=\text { agree, and } 4=\text { strongly agree. }\end{array}$} \\
\hline \multicolumn{6}{|c|}{$\begin{array}{l}\text { †Original survey question(s): Below is a list of stakeholder engagement roles DSTs can fulfill in conservation planning. When providing a response, } \\
\text { please think of DSTs you are familiar with. Please indicate your level of disagreement or agreement with the stakeholder engagement roles DSTs } \\
\text { should fulfill. Measured on a 4-point scale, where } 1=\text { strongly disagree, } 2=\text { disagree, } 3=\text { agree, and } 4=\text { strongly agree. }\end{array}$} \\
\hline \multicolumn{6}{|c|}{ ‡Mean scores for DST users. } \\
\hline \multicolumn{6}{|c|}{ §Mean scores for DST nonusers. } \\
\hline
\end{tabular}

$<0.001)$. Similarly, DST users scored significantly higher on the factor that they can effectively communicate DST results to farmers in the watershed, compared to
DST nonusers $(Z=-5.15, p<0.001)$. Taken together, although technical and stakeholder engagement roles of DSTs were desired by both users and nonusers, users were signifi- cantly more skilled, and had a higher level of self-efficacy, to engage in the desired conservation planning roles of DSTs. 
Table 6

Decision support tool (DST) users and nonusers' skills, abilities, and self-efficacy related to learning about and using DSTs.

\begin{tabular}{|c|c|c|c|c|c|}
\hline $\begin{array}{l}\text { Reasoned } \\
\text { Action Approach } \\
\text { comparative theme }\end{array}$ & Survey items $¥$ & $\mathbf{Z}$ & $\begin{array}{l}\text { DST users } \S \\
\text { (SD) }\end{array}$ & $\begin{array}{l}\text { DST nonusers } \| \\
\text { (SD) }\end{array}$ & $\boldsymbol{n}$ \\
\hline \multirow[t]{8}{*}{$\begin{array}{l}\text { Annual control- } \\
\text { skills and abilities* }\end{array}$} & $\begin{array}{l}\text { 1. I am proficient in using common Analytical tools (e.g., GIS, } \\
\text { hydrologic and sediment transport models) }\end{array}$ & $-2.35 * *$ & $3.38(1.04)$ & $3.01(1.10)$ & 205 \\
\hline & $\begin{array}{l}\text { 2. I am aware of water quality and ecological assessment } \\
\text { methods and techniques (e.g., water quality sampling and } \\
\text { analyses, habitat and biological indices) }\end{array}$ & $-2.14 * *$ & $3.71(0.87)$ & $3.43(0.95)$ & 204 \\
\hline & $\begin{array}{l}\text { 3. I am capable of persuading watershed stakeholders to } \\
\text { work together }\end{array}$ & $-2.39 * *$ & $3.54(0.68)$ & $3.29(0.74)$ & 203 \\
\hline & $\begin{array}{l}\text { 4. I can communicate effectively with different watershed } \\
\text { stakeholders }\end{array}$ & $-2.72 * * *$ & $3.82(0.55)$ & $3.58(0.71)$ & 203 \\
\hline & 5. I am able to adapt messages to suit the audience & $-2.24 * *$ & $3.83(0.65)$ & $3.62(0.67)$ & 203 \\
\hline & $\begin{array}{l}\text { 6. I am capable of building and utilizing relationships with } \\
\text { farmers and other key stakeholders in the watershed }\end{array}$ & $-2.45 * *$ & $3.91(0.62)$ & $3.70(0.67)$ & 203 \\
\hline & $\begin{array}{l}\text { 7. I can facilitate identification and creation of shared interests } \\
\text { and goals with watershed stakeholders }\end{array}$ & $-2.20 * *$ & $3.65(0.62)$ & $3.42(0.72)$ & 204 \\
\hline & $\begin{array}{l}\text { 8. I can use outputs/results from GIS based DSTs to engage } \\
\text { with farmers }\end{array}$ & $-4.75 * * *$ & $3.75(0.69)$ & $3.27(0.73)$ & 205 \\
\hline \multirow{2}{*}{$\begin{array}{l}\text { Perceived behavioral } \\
\text { control } \dagger\end{array}$} & 1. I believe I have the technical skills to run the DSTs & $-5.85 * * *$ & $3.94(0.71)$ & $3.26(0.90)$ & 213 \\
\hline & $\begin{array}{l}\text { 2. I believe I can effectively communicate DST results to farmers } \\
\text { in the watershed }\end{array}$ & $-5.15 * * *$ & $3.79(0.71)$ & $3.22(0.85)$ & 215 \\
\hline
\end{tabular}

$* * p<0.05, * * * p<0.01$ based on Mann-Whitney U test.

* Original survey question: Please indicate your level of disagreement or agreement with the following statements about your technical abilities and interactions with stakeholders.

†Original survey question: Please indicate your level of disagreement or agreement with the following statements that may affect your learning about and use of DSTs.

$¥$ Statements about respondents' skills and abilities, and perceived behavioral control was measured on a 5-point scale, where 1 = strongly disagree, 2 = disagree, 3 = neither agree nor disagree, 4 = agree, and 5 = strongly agree .

$\S$ Mean scores for DST users.

||Mean scores for DST nonusers.

Reasoned Action Approach Framework and DSTs: Barriers to Learning about and Using DSTs. Drawing upon the RAA framework, we were also interested in exploring actual and perceived behavior controls experienced by agency staff from an organizational perspective. We assessed actual behavioral control by asking respondents about factors that may affect their learning about and use of DSTs (table 7). Results suggested that several factors differently acted as barriers for DST users and nonusers. For example, a comparison between the statement "My current workload makes it difficult for me to learn about new DSTs," measured on a scale of 1 (strongly disagree) to 5 (strongly agree), had a mean score of 3.85 ( $\mathrm{SD}=0.92$, $n=113$ ) for DST users and a mean score of 3.48 (SD $=0.83, n=101$ ) for DST nonusers. We conducted a Mann-Whitney U test to determine whether there was a statistical difference in how DST users and nonusers perceive barriers to learning about and using DSTs. Results indicated that DST users expe- rience the barrier of their current workload making it difficult for them to learn about new DSTs significantly more than DST nonusers $(Z=-3.25, p=0.001)$. Similarly, a Mann-Whitney U test indicated that DST users experience the barrier of conservation offices/agencies lacking the staffing capacity to learn about new DSTs significantly more than DST nonusers $(Z=-3.66, p<$ $0.001)$. Lack of organizational funding to participate in DSTs training opportunities was another barrier that DST users experienced significantly more than DST nonusers $(Z=-2.52, p=0.012)$. Whereas DST users identified lack of training opportunities in their county/watershed to learn about new DSTs as a barrier $(\mathrm{M}=3.55, \mathrm{SD}=0.89, n$ $=113)$, their mean scores were statistically not different from DST nonusers. Overall, whereas DST users are highly self-efficacious (see "Reasoned Action Approach [RAA] Framework and DSTs: Desired Roles of DSTs and DST Related Skills and Abilities" section), they also experienced several barriers to engage in DST related behaviors significantly more than DST nonusers. Therefore, it was not surprising that DST users scored significantly lower with respect to the perception that their decision to participate in a training session on DSTs is totally within their control, compared to DST nonusers $(Z=-2.15, p=0.032)$. These findings indicate that DST users and nonusers perceive barriers related to learning about and using DSTs differently.

Reasoned Action Approach Framework and DSTs: Attitudes, Perceived Norms, and Behavioral Intentions Related to DSTs. Having a positive or negative attitude toward performing the behavior and the perceived social pressure to engage or not engage in the behavior are RAA constructs that are expected to affect behavioral intention, i.e., someone's intention to perform the behavior (Fishbein and Ajzen 2011). While predicting behavioral intention and subsequent performance of DST related behaviors is beyond the score of this study, we were interested in 
Table 7

Decision support tool (DST) users and nonusers' perceptions of barriers related to learning about and using DSTs.

\begin{tabular}{|c|c|c|c|c|c|}
\hline $\begin{array}{l}\text { Reasoned Action Approach } \\
\text { comparative theme }\end{array}$ & Survey items $†$ & $\mathbf{Z}$ & DST users $¥$ (SD) & DST nonusers $§$ (SD) & $n$ \\
\hline \multirow[t]{3}{*}{ Actual control* } & $\begin{array}{l}\text { 1. My current workload makes it difficult for me to } \\
\text { learn about new DSTs }\end{array}$ & $-3.25 * * *$ & $3.85(0.92)$ & $3.48(0.83)$ & 214 \\
\hline & $\begin{array}{l}\text { 2. Conservation offices/agencies lack the staffing } \\
\text { capacity to learn about new DSTs }\end{array}$ & $-3.66 * * *$ & $3.81(0.95)$ & $3.39(0.85)$ & 213 \\
\hline & $\begin{array}{l}\text { 3. There is a lack of organizational funding to } \\
\text { participate in DSTs training opportunities }\end{array}$ & $-2.52 * *$ & $3.55(0.92)$ & $3.28(0.67)$ & 214 \\
\hline Perceived behavioral control* & $\begin{array}{l}\text { 1. I feel that my decision to participate in a training } \\
\text { session on DSTs is totally within my control }\end{array}$ & $-2.15 * *$ & $2.70(0.98)$ & $2.95(0.82)$ & 214 \\
\hline \multicolumn{6}{|c|}{$\star * p<0.05, * * * p<0.01$ based on Mann-Whitney $U$ test. } \\
\hline \multicolumn{6}{|c|}{$\begin{array}{l}\text { * Original survey question: Please indicate your level of disagreement or agreement with the following statements that may affect your learning about } \\
\text { and use of DSTs. }\end{array}$} \\
\hline \multicolumn{6}{|c|}{$\begin{array}{l}\text { †Statements about respondents' skills and abilities, and perceived behavioral control was measured on a } 5 \text {-point scale, where } 1=\text { strongly disagree } \\
2 \text { = disagree, } 3=\text { neither agree nor disagree, } 4=\text { agree, and } 5=\text { strongly agree. }\end{array}$} \\
\hline
\end{tabular}

whether DST users and nonusers had different attitudes, perceived social norms, and behavioral intentions toward DST related behaviors. Subsequently, we conducted a Mann-Whitney U test to determine whether there was a difference between DST users and nonusers with respect to their attitude toward engaging in behaviors pertaining to learning about and using DSTs. Results indicated that DST users like the idea of learning about DSTs significantly more than DST nonusers $(Z=-3.06, p=0.002)$. Similarly, DST users believe that DSTs can be helpful in increasing the effectiveness of education and outreach programs with farmers significantly more than DST nonusers $(Z=$ $-3.15, p=0.002)$. Overall, for two out of five statements about attitude toward DSTs, a statistically significant difference in mean scores was found between DST users and nonusers (table 8). These findings indicate that DST users have somewhat more positive attitudes toward DSTs than DST nonusers.

We also conducted a Mann-Whitney U test to determine whether there was a difference in how DST users and nonusers valued the opinions of others with respect to engaging in behaviors related to learning about and using DSTs. Results indicated that DST users valued the opinions of their colleagues about whether to participate in DST training $(\mathrm{s})$ significantly more than DST nonusers $(Z=-3.22, p=0.001)$. Similarly, DST users valued the opinions of their colleagues about whether to run DSTs significantly more than DST nonusers $(Z=-5.47, p<$ 0.001). Overall, for five out of six statements about perceived social norms, a statistically significant difference in mean scores was found between DST users and nonusers. These findings indicate that perceived social norms affect DST users significantly more than DST nonusers with respect to engaging in DST related behaviors.

A Mann-Whitney U test was conducted to determine whether there was a difference in intention of DST users and nonusers with respect to engaging in behaviors pertaining to learning about and using DSTs. Results indicated that DST users' intention to learn about different DSTs is significantly more than DST nonusers $(Z=-3.95, p<0.001)$. Similarly, DST users' intention to participate in training session(s) about DSTs is significantly more than DST nonusers $(Z=-5.31$, $p=0.000)$. For all the behavioral intentions, a statistically significant difference in mean scores was found between DST users and nonusers. These findings indicate that intention of DST users to participate in DST related behaviors is significantly more than DST nonusers.

\section{Summary and Conclusions}

Conservation planning is a science-based process that is often facilitated by DSTs. Whereas technological advances, institutional support, and the pragmatic needs of conservation planning have led to the design and development of several DSTs (Cerf et al. 2012; Tomer and Locke 2011; Duriancik et al. 2008), most of the scholarship on DSTs focuses on uptake of DSTs by farmers and their advisors (Breuer et al. 2008; Carberry et al. 2002). Current scholarship, however, lacks an understanding of the use of DSTs by conservation agency staff in particular. More importantly, what facilitates, or potentially acts as a barrier, for uptake of DSTs by conservation agency staff? With the goal of fulfilling the aforementioned knowledge gaps, we conducted an online survey of conservation agency staff. Our objective was to generate a baseline understanding of the level of usage and awareness of DSTs, to conduct a comparative and descriptive investigation of technical and stakeholder engagement roles of DSTs, and use the RAA framework to compare DST related behaviors of DST users and nonusers.

Among all survey respondents as a group, approximately half of conservation agency staff used DSTs. Among users, field-scale DSTs were commonly used, sometimes as much as $90 \%$ of the time, whereas newer watershed-scale and less available DSTs were less commonly utilized. Almost half of our survey respondents were DST nonusers. Among nonusers, 22\% had at least heard of DSTs. There were differences in the DSTs surveyed in our study with respect to the current and past usage, and user awareness. The four DSTs that would be expected to be commonly used are in fact commonly used (table 4). Several of the DSTs that scored low in terms of their usage and awareness are specialized DSTs needed for broader scale planning. Moreover, these DSTs are newer, complex, or require training or local parameterization prior to their usage. Given that CEAP has stimulated evaluation and devel- 


\section{Table 8}

Decision support tool (DST) users and nonusers' attitudes, perceived norms, and behavioral intentions related to DSTs.

\begin{tabular}{|c|c|c|c|c|c|}
\hline $\begin{array}{l}\text { Reasoned } \\
\text { Action Approach } \\
\text { comparative theme }\end{array}$ & Survey items§ & $\boldsymbol{Z}$ & $\begin{array}{l}\text { DST users } \| \\
\text { (SD) }\end{array}$ & $\begin{array}{l}\text { DST nonusers\# } \\
\text { (SD) }\end{array}$ & $n$ \\
\hline \multirow{7}{*}{$\begin{array}{l}\text { Attitude toward behavior* } \\
\text { and perceived norm } †\end{array}$} & 1. I like the idea of learning about DSTs & $-3.06 * * *$ & $3.82(0.82)$ & $3.59(0.66)$ & 217 \\
\hline & $\begin{array}{l}\text { 2. I believe DSTs can be helpful in increasing the effectiveness } \\
\text { of education and outreach programs with farmers }\end{array}$ & $-3.15 * * *$ & $3.76(0.82)$ & $3.51(0.74)$ & 217 \\
\hline & 3. My colleagues would like me to participate in DST training(s) & $-3.22 * * *$ & $3.33(0.75)$ & $3.08(0.52)$ & 215 \\
\hline & 4. My colleagues would like me to run DSTs & $-5.47 * * *$ & $3.45(0.75)$ & $2.98(0.63)$ & 215 \\
\hline & $\begin{array}{l}\text { 5. Most people whose opinions I value would encourage me to } \\
\text { learn about new DSTs }\end{array}$ & $-5.10 * * *$ & $3.53(0.74)$ & $3.12(0.57)$ & 215 \\
\hline & $\begin{array}{l}\text { 6. People whose opinions I value would want me to use results } \\
\text { from DSTs to engage with farmers in the watershed }\end{array}$ & $-4.39 * * *$ & $3.53(0.74)$ & $3.16(0.63)$ & 215 \\
\hline & $\begin{array}{l}\text { 7. Watershed stakeholders would want me to use results from } \\
\text { DSTs to find solutions to their natural resource concerns }\end{array}$ & $-3.29 * * *$ & $3.46(0.77)$ & $3.18(0.72)$ & 216 \\
\hline \multirow[t]{4}{*}{ Behavioral intention $\ddagger$} & 1. I plan to learn about different DSTs & $-3.95 * * *$ & $3.54(0.72)$ & $3.17(0.72)$ & 214 \\
\hline & 2. I plan to participate in training session(s) about DSTs & $-5.31 * * *$ & $3.54(0.70)$ & $3.04(0.68)$ & 214 \\
\hline & 3. I expect to use DSTs to engage with farmers in the watershed & $-4.56 * * *$ & $3.38(0.77)$ & $2.94(0.71)$ & 214 \\
\hline & $\begin{array}{l}\text { 4. I expect to use DSTs to engage with other types of stakeholders } \\
\text { in the watershed }\end{array}$ & $-3.84 * * *$ & $3.36(0.75)$ & $2.98(0.71)$ & 213 \\
\hline
\end{tabular}

$* * * p<0.01$ based on Mann-Whitney U test.

*Original survey question: Please indicate your level of disagreement or agreement with the following statements about DSTs.

†Original survey question: Please indicate your level of disagreement or agreement with the following statements about who would like you to use DSTs. $\ddagger$ Original survey question: Please indicate your level of disagreement or agreement with the following statements about your intent to learn about and use DSTs.

$\S$ Statements about respondents' attitudes, perceived norms, and behavioral intentions was measured on a 5-point scale, where 1 = strongly disagree, 2 = disagree, 3 = neither agree nor disagree, 4 = agree, and 5 = strongly agree .

$\|$ Mean scores for DST users.

\#Mean scores for DST nonusers.

opment of both existing and new DSTs for over a decade, our expectation was that a bigger proportion of our survey respondents in CEAP-WAS sites would be DST users. It is thus reasonable to expect that watersheds, and conservation agencies within them, that have not been exposed to collaborative initiatives like CEAP, may have an even smaller proportion of DST users.

However, it is important to recognize that not all the DSTs surveyed in our study are similar with respect to their availability, documentation, and level of difficulty (table 1), thus limiting their usage and awareness. In addition, job duties of conservation agency staff may affect their usage/awareness of DSTs. Agency staff with direct conservation planning duties are more likely to be DST users than agency staff with conservation planning support roles. As we mentioned earlier, our sampling frame included both those with direct conservation planning responsibilities and those who support conservation planning, potentially resulting in a lower percentage of DST users in our sample.
We would also like to acknowledge that due to definition and usage of the term DST, some respondents may have answered "No" to the question regarding their usage of DSTs. They may not recognize conservation planning tools as DSTs, even though background information about DSTs was provided at the beginning of the survey, along with a few examples of DSTs. At least two respondents felt that they had incorrectly answered "No" to this question, and, upon contacting us, were sent a link to retake the survey. Despite these potential limitations, as our results suggest, the first step toward promoting learning and usage of DSTs among conservation agency staff would be to make them more aware of DSTs and their functionalities and make them more available to agency staff. Moreover, making DST training available and facilitating and supporting attendance at DST training sessions could be a substantial step toward facilitating adoption and use of DSTs.

Our findings suggest that a role current DSTs should fulfill, and future DSTs should strive for, is to facilitate engagement with watershed stakeholders, including farmers. We found that a majority of DST users had used output maps and data sets from DSTs for education and outreach with both farmers and other watershed stakeholders (table 3). Indeed, maps and data sets generated by DSTs are used by agency staff to engage farmers (Ranjan et al. 2019), and have the potential to motivate conservation behavior (Ranjan et al. 2020). This presents a potential opportunity for effective engagement with farmers, especially by including outputs on quantifiable environmental and economic benefits of conservation practices. Both DST users and nonusers predominantly agreed that DSTs should fulfill the stakeholder engagement roles listed in the survey. This is an important finding for future development and design of DSTs, as DST developers should be mindful of the stakeholder engagement needs of conservation agency staff, such as facilitating one-on-one as well as group discussion with farmers about conservation opportunities on their farm. Moreover, those who conduct and facilitate DST training sessions should ensure that conservation agency 
staff are not only trained in the technical functionalities of DSTs, but are also trained for stakeholder engagement, especially with respect to translating DSTs' results and communicating them to watershed stakeholders to support conservation adoption goals.

We assessed conservation agency staffs' perception of the conservation planning roles DSTs should fulfill and their related skills and abilities. We found that although both users and nonusers desired DSTs to fulfill several conservation planning roles, users were much more skilled with respect to their technical and stakeholder engagement abilities. Consequently, DST users had a significantly higher level of self-efficacy to engage in the desired conservation planning roles than DST nonusers. The main takeaway for DST developers and educators is that they could account for this skill gap when designing DSTs and when creating training modules, respectively. For example, although nonusers may not have the skills to run the DST, they might still desire and benefit from training on the use of DST results for application in conservation planning and outreach.

Using the RAA framework, we were also able to draw comparisons between DST users and nonusers with respect to their perceived and actual barriers to learning about and using DSTs. For example, despite being skilled and self-efficacious, DST users experienced limitations on their ability to control their behavior in terms of current workload, lack of staffing capacity, and organizational funding, significantly more than DST nonusers. These findings indicate that DST users and nonusers are not only differently skilled, but also perceive barriers related to learning about and using DSTs differently. Taken together, our findings indicate that DST users are skilled and self-motivated but are limited through behavioral constraints more so than DST nonusers. It is also possible that nonusers are not aware of constraints they would face toward using DSTs.

It is possible that the first step toward encouraging DST related behaviors is to build technical and stakeholder engagement skills. However, bridging the skill gap between DST users and nonusers should be complemented with taking steps toward removing the several aforementioned limitations on behaviors. One way to address this would be to direct resources not only toward capacity building of conservation agency staff but also toward overcoming barriers pertaining to their workload, to encourage use of DSTs. Providing these resources could also build agency staffs' self-efficacy and help overcome both the real and perceived barriers to learning about and using DSTs. Another way could be to implement a more consistent DST development and communication strategy for DSTs agency-wide Continued engagement and support of conservation partners' DST training and use through conservation technical assistance funding is another means to expand the use of DST products in conservation planning. This partner technical assistance approach provides initial exposure of NRCS or district staffs to new or more complex DSTs, and can expand on their current skills to bridge the gap between DST awareness and usage.

Using the RAA framework, we were also able to draw a comparison between DST users and nonusers with respect to their attitudes, perceived norms, and behavioral intentions. While breaking the real and perceived barriers is a logical first step toward encouraging the use of DSTs among conservation agency staff, our findings also suggest the need for a deeper understanding of conservation agency staffs' attitudes, perceived norms, and behavioral intentions. Overall, we found that DST users have a more positive attitude toward DSTs than nonusers. DST users also cared more about the opinions of their colleagues and others with respect to engaging in DST related behaviors than DST nonusers. Moreover, DST users' intentions to participate in DST related behaviors were significantly more than DST nonusers. DST educators should be mindful of these cognitive differences between conservation agency staff, especially between those who currently use DSTs and those who do not, when designing training modules. For example, in DST training sessions, educators should take steps to reinforce perceived norms of DST users, while making DST nonusers aware of the support and encouragement from their colleagues and other conservation agencies for using DSTs.

The goal of this study was to develop an understanding of the use of DSTs by conservation agency staff in CEAP watersheds and subsequently identify their education and training needs. Specifically, we were interested in the level of usage and awareness of DSTs, assessment of technical and stakeholder engagement roles of DSTs, and drawing a comparison between DST related behaviors of DST users and nonusers. We conducted an online survey of conservation agency staff in counties that either currently include or included a CEAP-WAS.We found that not all agency staff with direct planning responsibilities felt they used DSTs. Agency staff predominantly agreed that DSTs should fulfill stakeholder engagement roles. We also found significant differences between DST users and nonusers with respect to their attitudes, perceived norms, behavioral intentions, and real and perceived barriers to engaging in DST related behaviors.

Like all studies, this one has limitations. While our findings cannot be generalized to the education and training needs of all conservation agency staff nationwide due to our sampling design, they are broadly representative of the motivations for, and barriers to, the uptake of DSTs. Moreover, we feel that our results can be generalized to watersheds with similar initiatives like CEAP that have stimulated evaluation and development of DSTs or have supported watershed assessment or planning, such as NRCS water quality landscape conservation initiatives. Future scholarship can use a random sample to establish generalizability of our findings to the education and training needs of agency staff nationwide. Future scholarship can also survey only DST users to gain deeper insights into their education and training needs, especially with the goal of enhancing their ability to use the more complex watershed-scale DSTs. Another limitation of our study is that while we use the RAA framework, a framework often used to predict behaviors, we do not claim that a variable or a specific RAA construct is predictive of DST related behaviors. Moreover, we do not make any claims about the relative importance of a given RAA construct in predicting DST related behaviors. Despite these limitations, using the RAA framework allowed us to compare DST related behaviors of DST users and nonusers. Future scholarship should consider using the RAA framework to generate predictive models for DST related behaviors.

Owing to technological advancements, practical needs of conservation planning, and institutional support for initiatives like CEAP, DSTs have become an integral component of the conservation planning process. While DSTs are an essential toolkit for conservation planners, their uptake among conservation agency staff could be improved, particularly for watershed-scale DSTs. Use of 
watershed-scale assessment DSTs would help to plan more effective conservation options for water quality outcomes. To that effect, the findings from our study can be leveraged by DST developers and educators to encourage DST related behaviors, both among DST users and nonusers.

\section{Acknowledgements}

We would like to extend sincere thanks to the conservation agency staff who took the time to respond to our survey. Without their feedback, these analyses and insights would not have been possible.

\section{Disclaimer}

The findings and conclusions in this publication are those of the author(s) and should not be construed to represent any official USDA determination or policy.

\section{References}

Breuer, N.E., V.E. Cabrera, K.T. Ingram, K. Broad, and P.E. Hildebrand. 2008. AgClimate: A case study in participatory decision support system development. Climatic Change 87(3-4):385-403, doi:10.1007/ s10584-007-9323-7.

Brooks, E.S., S.M. Saia, J. Boll, L. Wetzel, Z.M. Easton, and T.S. Steenhuis. 2015.Assessing BMP effectiveness and guiding BMP planning using process-based modeling. Journal of the American Water Resources Association 51(2):34358, https://doi.org/10.1111/1752-1688.12296.

Carberry, P.S., Z. Hochman, R.L. McCown, N.P. Dalgliesh, M.A. Foale, P.L. Poulton, J.N.G. Hargreaves, D.M.G. Hargreaves, S. Cawthray, N. Hillcoat, and M.J. Robertson. 2002. The FARMSCAPE approach to decision support: Farmers', advisers', researchers', monitoring, simulation, communication and performance evaluation. Agricultural Systems 74(1):141-77, doi:10.1016/ S0308-521X(02)00025-2.

Cechova, K., D.C. Flanagan, J.R. Frankenberger, and B.W. Zuercher. 2010. WEPP model application in CEAP watersheds in NE Indiana. ASABE Paper No. 1008827. St. Joseph, MI: American Society of Agricultural and Biological Engineers.

Cerf, M., M.H. Jeuffroy, L. Prost, and J.M. Meynard. 2012. Participatory design of agricultural decision support tools: Taking account of the use situations. Agronomy for Sustainable Development 32(4):899-910, doi:10.1007/ s13593-012-0091-z.

Chan, R., C. Baffaut, A. Thompson, and J. Sadler. 2017. Validating the Soil Vulnerability Index for a claypan watershed. Catena 148(Part 2):185-194.

Cosgrove, D., D. Undersander, and J. Cropper. 2001. Guide to Pasture Condition Scoring. Washington, DC: USDA Natural Resources Conservation Service, Grazing Lands Technology Institute.

Dabney, S.M., D.C. Yoder, D.A.N. Vieira, and R.L. Bingner. 2011. Enhancing RUSLE to include runoff-driven phenomena. Hydrological Processes 25(9):1373-90, doi:10.1002/hyp.7897.

Dillman, D.A., J.D. Smyth, and L.M. Christian. 2014. Internet, Phone, Mail, and Mixed-Mode Surveys: The Tailored Design Method. Hoboken, NJ: John Wiley and Sons.

Duriancik, L.F., D. Bucks, J.P. Dobrowolski, T. Drewes, S.D. Eckles, L. Jolley, R.L. Kellogg, D. Lund, J.R. Makuch, M.P. O'Neill, C.A. Rewa, M.R. Walbridge, R. Parry, and M.A. Weltz. 2008. The first five years of the Conservation Effects Assessment Project. Journal of Soil and Water Conservation 63(6):185A-197A, doi:10.2489/jswc.63.6.185A.

Fishbein, M., and I. Ajzen. 2011. Predicting and Changing Behavior: The Reasoned Action Approach. New York: Psychology Press.

Flanagan, D.C., J.R. Frankenberger, and J.C. Ascough II. 2012. WEPP: Model use, calibration, and validation. Transactions of the ASABE 55(4):1463-1477.

Flanagan, D.C., and S.J. Livingston, eds. 1995. Water Erosion Prediction Project (WEPP) Version 95.7: User Summary. NSERL Report No. 11. West Lafayette, ID: USDA Agricultural Research Service, National Soil Erosion Research Laboratory.

Foster, G.R., D.C. Yoder, G.A. Weesies, and T.J. Toy. 2001. The Design Philosophy Behind RUSLE2: Evolution of an Empirical Model, eds. J.C. Ascough II and D.C. Flanagan, 95-98. In Soil Erosion Research for the 21st Century, Proceedings of the International Symposium, 3-5 January 2001, Honolulu, Hawaii. St. Joseph, MI: American Society of Agricultural Engineers.

Hagen, L.J., L.E. Wagner, J. Tatarko, E.L. Skidmore, A.A. Durar, J.L. Steiner, H.H. Schomberg, A. Retta, D.V. Armbrust, T.M. Zobeck, P.W. Unger, D. Ding, and I. Elminyawi. 1995. Wind Erosion Prediction System: Technical description. In Proceedings of WEPP/WEPS Symposium, August 9-11, Des Moines, Iowa. Ankeny, IA: Soil and Water Conservation Society.

Kleinman, P.J.A., A.N. Sharpley, A.R. Buda, Z.M. Easton, J.A. Lory, D.L. Osmond, D.E. Radcliffe, N.O. Nelson, T.L.Veith, and D.G. Doody. 2017. The promise, practice, and state of planning tools to assess site vulnerability to runoff phosphorus loss. Journal of Environmental Quality 46:1243-1249, doi:10.2134/jeq2017.10.0395.

Lee, S., A.M. Sadeghi, G.W. McCarty, C. Baffaut, S. Lohani, L.F. Duriancik, A. Thompson, I.Y. Yeo, and C. Wallace. 2018. Assessing the suitability of the Soil Vulnerability Index (SVI) on identifying croplands vulnerable to nitrogen loss using the SWAT model. Catena 167:1-12, https://doi.org/10.1016/j.catena.2018.04.021.

Lemunyon, J.L., and R.G. Gilbert. 1993. The concept and need for a phosphorus assessment tool. Journal of Production Agriculture 6(4):483-496.

Liu, Y., S. Li, C.W. Wallace, I. Chaubey, D.C. Flanagan, L.O. Theller, and B.A. Engel. 2017. Comparison of computer models for estimating hydrology and water quality in an agricultural watershed. Water Resources Management 31:3641, https://doi.org/10.1007/s11269-017-1691-9.
Maresch, W., M.R. Walbridge, and D. Kugler. Enhancing conservation on agricultural landscapes: A new direction for the Conservation Effects Assessment Project. Journal of Soil and Water Conservation 63(6):198A-203A.

McCool, D.K., L.C. Brown, G.R. Foster, C.K. Mutchler, and L.D. Meyer. 1987. Revised slope steepness factor for the Universal Soil Loss Equation. Transactions of the ASAE 30:1387-1396.

McCool, D.K., G.R. Foster, C.K. Mutchler, and L.D. Meyer. 1989. Revised slope length factor in the Universal Soil Loss Equation. Transactions of the ASAE 30:1571-1576.

McLellan, E.L., K.E. Schilling, C.F. Wolter, M.D. Tomer, S.A. Porter, J.A. Magner, D.R. Smith, and L.S. Prokopy. 2018. Right practice, right place: A conservation planning toolbox for meeting water quality goals in the Corn Belt. Journal of Soil and Water Conservation 73(2):29A34A, doi:10.2489/jswc.73.2.29A.

Moriasi, D.N., K.W. King, D.D. Bosch, D.L. Bjorneberg, S. Teet, J.A. Guzman, and M.R. Williams. 2016. Framework to parameterize and validate APEX to support deployment of the Nutrient Tracking Tool. Agricultural Water Management 177:146-164.

Norfleet, M., E. Steglich, S. Quisenberry, J. Bagdon, M.G. Christoph, and E. Hesketh. 2015. Introduction to the USDA-NRCS Stewardship Tool for Environmental Performance (STEP). Presented at American Society of Agronomy 2015 Annual Meeting, Minneapolis, Minnesota.

Osmond, D.L., D.W. Meals, D.L.K. Hoag, and M. Arabi, eds. 2012. How to Build Better Agricultural Conservation Programs to Protect Water Quality: The National Institute of Food and Agriculture-Conservation Effects Assessment Project Experience. Ankney, IA: Soil and Water Conservation Society.

Pellant, M., P. Shaver, D.A. Pyke, and J.E. Herrick. 2005. Interpreting indicators of rangeland health, version 4. Technical Reference 1734-6. Denver, CO: US Department of the Interior, Bureau of Land Management, National Science and Technology Center. Ranjan, P., A.S. Singh, M.D. Tomer, A.M. Lewandowski, and L.S. Prokopy. 2019. Lessons learned from using a decision-support tool for precision placement of conservation practices in six agricultural watersheds in the US Midwest. Journal of Environmental Management 239:57-65.

Ranjan, P., A.S. Singh, M.D. Tomer, A.M. Lewandowski, and L.S. Prokopy. 2020. Farmer engagement using a precision approach to watershed-scale conservation planning: What do we know? Journal of Soil and Water Conservation, doi:10.2489/jswc.2020.00072.

Renard, K.G., G.R. Foster, G.A. Weesies, and J.P. Porter. 1991. RUSLE: Revised Universal Soil Loss Equation. Journal of Soil and Water Conservation 46(1):30-33.

Rose, D.C., W.J. Sutherland, C. Parker, M. Lobley, M. Winter, C. Morris, S. Twining, C. Ffoulkes, T. Amano, and L.V. Dicks. 2016. Decision support tools for agriculture: Toward effective design and delivery. Agricultural Systems 149:165-74, doi:10.1016/j.agsy.2016.09.009. 
Saleh, A., O. Gallego, E. Osei, H. Lal, C. Gross, S. McKinney, and H. Cover. 2011. Nutrient Tracking Tool: A userfriendly tool for calculating nutrient reductions for water quality trading. Journal of Soil and Water Conservation 66(6):400-410, https://doi.org/10.2489/jswc.66.6.400.

Sanderson, M.A., S.C. Goslee, J. Gonet, and R. Stout. 2009. Pasture monitoring at a farm scale with the USDA NRCS pasture condition score system. Journal of Soil and Water Conservation 64(6):423-433, doi:10.2489/ jswc.64.6.423.

Sharpley, A.N., J.L. Weld, D.B. Beegle, P.J.A. Kleinman, W.J. Gburek, P.A. Moore, and G. Mullins. 2003. Development of phosphorus indices for nutrient management planning strategies in the U.S. Journal of Soil Water Conservation 58(3):137-152.

Thompson, A., C. Baffaut, S. Lohani, L. Duriancik, L. Norfleet, and K. Ingram. 2020. Purpose, development, and synthesis of the Soil Vulnerability Index for inherent vulnerability classification of cropland soils. Journal of Soil Water Conservation 75(1):1-11, https://doi. org/10.2489/jswc.75.1.1.

Tomer, M.D., D.E. James, J.A. Kostel, and J. Bean. 2015. Siting Multiple Conservation Practices in a Tile-Drained Watershed Using LiDAR Topographic Data. In GIS Applications in Agriculture, Volume Four: Conservation Planning, ed.T. Mueller and G.F. Sassenrath. Boca Raton, FL: CRC Press.

Tomer, M.D., and M.A. Locke. 2011. The challenge of documenting water quality benefits of conservation practices: A review of USDA-ARS's Conservation Effects Assessment Project Watershed Studies. Water Science and Technology 64(1):300-310, doi:10.2166/ wst.2011.555.

Tomer, M.D., S.A. Porter, K.M.B. Boomer, D.E. James, J.A. Kostel, M.J. Helmers, T.M. Isenhart, and E. McLellan. 2015.Agricultural Conservation Planning Framework: 1. Developing multipractice watershed planning scenarios and assessing nutrient reduction potential. Journal of Environmental Quality 44(3):754, doi:10.2134/ jeq2014.09.0386.

USDA NRCS (Natural Resources Conservation Service). 2012.Assessment of the Effects of Conservation Practices on Cultivated Cropland in the Upper Mississippi River Basin. Washington, DC: USDA Natural Resources Conservation Service. https://www.nrcs.usda.gov/ Internet/FSE_DOCUMENTS/stelprdb1042093.pdf.

Vaske,J.J.2008. Survey Research and Analysis:Applications in Parks, Recreation and Human Dimensions. Edmonton, Alberta:Venture Publishing.

Webb, N.P., J.E. Herrick, J.W. Van Zee, E.M. Courtright, C.H.Hugenholtz, T.M. Zobeck, G.S. Okin,T.E. Barchyn, B.J. Billings, R. Boyd, S.D. Clingan, B.F. Cooper, M.C. Duniway,J.D.Derner, F.A. Fox, K.M. Havstad, P.Heilman, V. LaPlante, N.A. Ludwig, L.J. Metz, M.A. Nearing, M.L. Norfleet, F.B. Pierson, M.A. Sanderson, B.S. Sharratt, J.L. Steiner, J. Tatarko, N.H. Tedela, D. Toledo, R.S. Unnasch, R.S.Van Pelt, and L. Wagner. 2016. The National Wind
Erosion Research Network: Building a standardized long-term data resource for aeolian research, modeling and land management. Aeolian Research 22:23-36, doi:10.1016/j.aeolia.2016.05.005.

Williams, J.R., and R.C. Izaurralde. 2005. The APEX model BRC Rep. 2005-02. Temple, TX: Blackland Research Center, Texas A\&M University. 